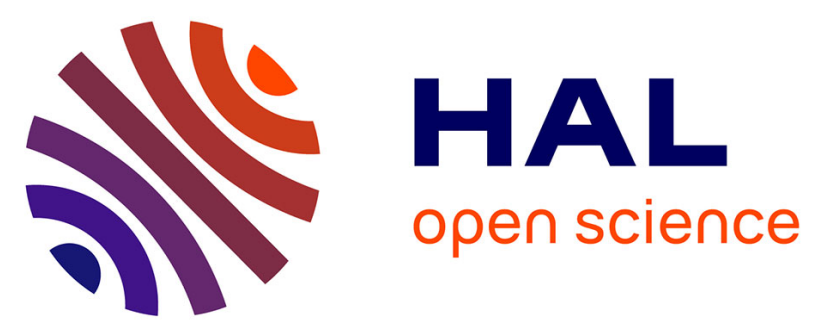

\title{
A Generalized Caprine-like Hypoplasia Syndrome is localized within a 6-cM interval on bovine chromosome 13 in the Montbeliarde breed
}

Amandine Duchesne, L Manciaux, M Gautier, Sandrine Floriot, Cécile Grohs, Sébastien Fritz, T Druet, Francois F. Schelcher, A Ducos, Andre Eggen

\section{To cite this version:}

Amandine Duchesne, L Manciaux, M Gautier, Sandrine Floriot, Cécile Grohs, et al.. A Generalized Caprine-like Hypoplasia Syndrome is localized within a 6-cM interval on bovine chromosome 13 in the Montbeliarde breed. Animal Genetics, 2008, 39 (2), pp.112-120. 10.1111/j.1365-2052.2007.01688.x . hal-02659723

\section{HAL Id: hal-02659723 \\ https://hal.inrae.fr/hal-02659723}

Submitted on 31 May 2020

HAL is a multi-disciplinary open access archive for the deposit and dissemination of scientific research documents, whether they are published or not. The documents may come from teaching and research institutions in France or abroad, or from public or private research centers.
L'archive ouverte pluridisciplinaire HAL, est destinée au dépôt et à la diffusion de documents scientifiques de niveau recherche, publiés ou non, émanant des établissements d'enseignement et de recherche français ou étrangers, des laboratoires publics ou privés. 


\title{
A Generalized Caprine-like Hypoplasia Syndrome is localized within a 6-cM interval on bovine chromosome 13 in the Montbéliarde breed
}

\author{
A. Duchesne*, L. Manciaux ${ }^{\dagger}$, M. Gautier* , S. Floriot* , C. Grohs* , S. Fritz ${ }^{\ddagger}$, T. Druet $^{\S}$, F. Schelcher ${ }^{\natural}$, \\ A. Ducos** and A. Eggen* \\ *Laboratoire de Génétique Biochimique et de Cytogénétique, Département de Génétique Animale, INRA-CRJ, 78350 Jouy-en-Josas, France. \\ ${ }^{+}$CEIA du Doubs et du Territoire de Belfort, 25640 Roulans, France. ${ }^{*}$ Union Nationale des Coopératives d'Elevage et d'Insémination Animale \\ (UNCEIA), 75595 Paris, France. ${ }^{5}$ Station de Génétique Quantitative Appliquée, Département de Génétique Animale, INRA-CRJ, 78350 \\ Jouy-en-Josas, France. "UMR INRA-ENVT 1225, Interactions Hôte Agent Pathogène, Ecole Nationale Vétérinaire de Toulouse, 31076 \\ Toulouse, France. **UMR INRA-ENVT 898, Cytogénétique des Populations Animales, Ecole Nationale Vétérinaire de Toulouse, 31076 \\ Toulouse, France
}

\section{Summary}

\begin{abstract}
Caprine-like Generalized Hypoplasia Syndrome (or SHGC) is a new hereditary disorder described in the Montbéliarde breed. We report here the characterization of this new disease, based on the visual examination of animals affected by SHGC, and on physiological and biochemical studies undertaken on samples of both SHGC and normal animals. Biological samples for more than 150 affected calves and their parents have been collected over the past 4 years within the framework of the Bovine Genetic Disease Observatory. First, pedigree analyses showed that the mode of inheritance is most probably autosomal recessive. Then, a genome scan with 113 animals and 140 microsatellite markers revealed a single locus within a 35-cM region on bovine chromosome 13. Genotypes of 261 animals for 18 new microsatellite markers from the region confirmed the localization of the disorder to a 6-cM interval. Finally, based on the analysis of haplotypes in 463 Montbéliarde sires, we estimated the frequency of the SHGC mutated allele in the population and could propose a strategy for the systematic eradication of this disorder in the near future.
\end{abstract}

Keywords cattle, Generalized Caprine-like Hypoplasia Syndrome, genetic disease.

\section{Introduction}

Cattle have been highly selected during the past 50 years to improve animal performances. During this period, breeding practices have changed considerably, especially with the development of artificial insemination (AI). Although very successful in terms of improvement of production traits, the widespread use of a few AI elite sires has led to severe genetic bottlenecks and increased inbreeding (0.04\%, $0.12 \%$ and $0.2 \%$ in the 1970 s, 1980 s and 1990 s respectively in the Holstein population for 26 generations studied; Thompson et al. 2000). In France, the effective number of ancestors for females born between 1993 and 1996 was estimated at 30 and 33 respectively in the Montbéliarde and

Address for correspondence

A. Eggen, Laboratoire de Génétique Biochimique et de Cytogénétique, Département de Génétique Animale, INRA-CRJ, 78350 Jouy-en-Josas, France.

E-mail: andre.eggen@jouy.inra.fr

Accepted for publication 24 October 2007
Holstein-Friesian breeds, while the number of ancestors responsible for $50 \%$ of the genes present in the populations was estimated at 12 and 16 respectively (Moureaux et al. 2000). These particular genetic structures increase the risk of rapid and massive diffusion of deleterious recessive genes (Hartl 1994). Moreover, inbreeding has been shown to be negatively associated with survival (Thompson et al. 2000). The recent outspread stories of BLAD (Nagahata 2004) and CVM (Thomsen et al. 2006) in the Holstein-Friesian breed clearly show that such a risk is not only theoretical.

Currently, 369 hereditary diseases are described in cattle (OMIA, http://omia.angis.org.au/). According to Huston (1993), approximately $60 \%$ of the disorders are inherited as autosomal recessive characters. Such hereditary diseases do not affect all bovine breeds equally, because most of these diseases are detected in breeds in which AI has been intensively used for several generations. For example, in HolsteinFriesian and Jersey breeds 83 and 40 genetic abnormalities respectively have been described (Millar et al. 2000).

However, there are some exceptions such as the Montbéliarde breed, in which inbreeding is comparable with that 
observed in Holstein-Friesian but no abnormalities had been reported until recently (Millar et al. 2000).

Indeed, in the 1990s, a new hereditary disease appeared in the Montbéliarde breed population, with the first few cases reported in the progeny of two sires. From 1999, affected animals were collected more systematically, i.e. ten cases between 1999 and 2000, and their number has increased ever since with up to 70 cases reported in 2004 2005. Since the end of 2001, affected animals have been recorded within the framework of the Bovine Genetic Disease Observatory (BGDO), which was created in France at this time to enhance the detection and the control of hereditary disorders (Ducos et al. 2004).

This new disease is called 'Syndrome d'Hypoplasie Généralisée Capréoliforme' (SHGC) in French (equivalent to 'Generalized Caprine-like Hypoplasia Syndrome' in English) because of the characteristic elongated caprine-like head of affected animals. It is characterized by low birth weight (60-70\% of the normal weight), pronounced muscular insufficiency and delayed development during the entire life of the animal. In addition, affected animals exhibit a long and thin head (often called 'deer head' or 'sheep head') and partial coat depigmentation in the red zones. Although they may appear to be relatively healthy, the value of SHGC animal carcasses is depreciated due to the persistent growth retardation associated with a low weight (decreased by $50 \%$ compared to normal ones). Thus, economic losses are important for breeders, which explain the need to eradicate SHGC in the Montbéliarde population.

In this paper, we report the characterization of this new disease, based on the visual examination of animals affected by SHGC, and on physiological and biochemical studies undertaken on samples of both SHGC and normal animals. A genome scan, fine mapping and haplotype studies were also performed, which revealed that the SHGC disease is strongly linked to bovine chromosome 13 and which identified a common paternal haplotype in all affected animals, spanning a $\sim 6 \mathrm{cM}$ region. Finally, based on the analysis of haplotypes in 463 Montbéliarde sires, we estimated the frequency of the SHGC mutated allele in the population and could propose a strategy for the systematic eradication of this disorder in the near future.

\section{Materials and methods}

\section{Clinical evaluation of the disease}

To ensure uniform description of the disorder, a single veterinarian carried out the phenotyping by visual examination of all the affected calves collected by the BGDO.

Six SHGC animals were autopsied at the large animal clinic of the National Veterinary School of Toulouse. Classical histological analyses were performed on the following tissues: brain, thoracic and lumbar spinal cord, left ventricle of the heart, liver, lung, kidney, spleen, thyroid and adrenal glands, ileal lymph gland and different muscles (diaphragm, iliopsoas, adductor and common mass). Before slaughter, a complete checkup was carried out including urinalysis, routine haematology and serum/plasma chemistry (sodium, potassium, chloride, $\mathrm{CO}_{2}$, fibrinogen, urea, creatinine, calcium, magnesium, phosphates, aspartate aminotransferase, creatine kinase, $\gamma$-glutamyltransferase, glucose, copper, zinc and tyroxine). Moreover, selenium-dependent glutathione peroxidase (GSH-Px) and superoxide dismutase were measured in the red blood cells. Tests for bovine viral diarrhoea antigens, serology for brucellosis and faecal examination were also carried out.

Haemoglobin, total proteins, copper, zinc and GSH-Px were analysed in another laboratory on ten SHGC calves, their dams and 20 other contemporary calves (slightly younger and older than the SHGC calves) collected directly at the same farms.

\section{Animals used for the molecular genetics investigations}

Two hundred and sixty-one animals of the Montbéliarde breed collected by the BGDO during the past 3 years were studied, including 138 SHGC calves, four normal calves, 103 dams and 16 sires. These animals originated from four French departments (Ain, Doubs, Haute-Saône and Territoire de Belfort). To reduce cost and time, the genome scan was performed on a subpanel of 113 animals from the 261 collected animals. These 113 animals came from nine families consisting of 52 affected calves, their 52 mothers and nine sires. However, the fine-mapping studies were performed on the entire animal set (i.e. 261 animals belonging to 22 families), which were all paternal half-sib families with up to 39 affected half-sibs per sire and an average of 6.5 half-sibs per sire.

Finally, to evaluate the frequency of SHGC in the Montbéliarde breed, 463 Montbéliarde sires were used (including historical sires, AI sires and AI candidate sires).

Blood samples were taken from calves and dams and semen samples were taken from sires.

\section{Pedigree analysis}

The pedigrees were analysed using PEDIG software (Boichard 2002), to detect ancestor(s) common to all the affected animals.

\section{DNA extraction, markers and genotyping}

Genomic DNA was extracted from blood samples with the Genisol Maxi-Prep kit (AbGene) or from semen with a phenol/chloroform extraction according to standard procedures.

One hundred and forty publicly available microsatellite markers (Table S1) were used for the genome scan. The order of the markers and the genetic distances were estimated from the available genetic maps (Ihara et al. 
2004). These 140 markers covered a total length of $2431 \mathrm{cM}$ and were distributed along the 29 autosomes, with on average one marker every $18 \mathrm{cM}$. As males and females were equally affected by SHGC, the X and Y chromosomes were not studied.

Based on the preliminary localization of SHGC (i.e. a region on BTA13 spanning 30-35 cM between microsatellite markers ABS10 and HUJ616 and on mapping information available for BTA13), 18 markers were selected from a 35-cM interval in the existing bovine genetic map (Ihara et al. 2004) to maximize the coverage of the critical region. The characteristics of these new markers are given in Table S2.

The genotyping procedure consisted in a multiplex fluorescent PCR amplification with one fluorescent end-labelled primer (Eurogentec). According to the dye fluorochrom and to the PCR product length, the 18 microsatellites were assembled into four multiplexes. PCR reactions were performed using the Multiplex PCR kit (Qiagen) on a PTC-100 thermocycler (MJ Research) in a 10- $\mu$ l final volume (Gautier et al. 2006).

BAC library screening, radiation hybrid mapping and map construction

Microsatellite markers used for fine mapping and genes from the region were mapped by PCR on a 94-cell-line radiation hybrid panel (Williams et al. 2002), and the CARTHAGENE software (de Givry et al. 2005) was used to perform twopoint and multipoint analyses of the radiation hybrid data to provide a comprehensive map of the region.

The four-genome equivalent INRA bovine BAC library containing 105984 clones was screened by PCR for each locus as previously described (Eggen et al. 2001; Gautier et al. 2002). The BAC contigs of the region were constructed by integrating the resulting marker information to available physical mapping information (Schibler et al. 2004) (http://locus.jouy.inra.fr/htdocs/fpc/cattle_bac_map. html).

\section{Linkage analysis}

Because the mode of inheritance of SHGC was not clear, non-parametric linkage analyses were performed using the GENEHUNTER software (Kruglyak et al. 1996). Analyses were performed for each chromosome separately based on the order from available maps (Ihara et al. 2004), and a simple Bonferroni correction was used to account for multiple testing (i.e. 29 chromosomes). In cases where families were too large for GENEHUNTER, they were split in subfamilies, which were analysed separately.

\section{Haplotyping}

Due to the structure of the population (up to 39 dams per sire), the most likely haplotypes of the 261 collected animals were constructed using the MERLIN software (Abecasis et al. 2002) with the 'best' option. For the 463 sires used in the estimation of the SHGC frequency in the Montbéliarde breed, haplotype reconstruction was performed using available pedigree information (Bolard \& Boichard 2002).

\section{Association tests}

Family-based association tests were performed as described in Lake et al. (Lake et al. 2000) using the FвAT software (http://www.biostat.harvard.edu/ fbat/fbat.htm). FBAT was used with the recessive model and the bi-allelic mode, where each allele is tested separately, resulting in multiple, single degree-of-freedom tests. As above, in cases where families were too large for FвAт, they were split in subfamilies, which were analysed separately.

Estimation of the frequency of the SHGC allele in the population

After reconstructing haplotypes for the 463 Montbéliarde sires, identical-by-descent (IBD) probabilities were calculated between the haplotypes of the 463 sires and the core IBD disease carrier haplotype (Meuwissen \& Goddard 2001).

\section{Results}

\section{Analysis of the phenotype}

The phenotype of animals affected by SHGC was assessed by visual examination. Affected animals present a wide range of clinical features, with a variable expressivity. However, three features are critical to confirm the diagnosis of SHGC: (i) low birth weight (around 30-35 kg) and a continuing delay in development (Fig. 1a), (ii) long and thin head and (iii) partial coat depigmentation in the red zones (Fig. 1b). Most SHGC calves have white ears, in contrast with the red ears characteristic of the Montbéliarde breed. Another characteristic of the Montbéliarde breed, the homogeneity of the coloured coat regions without any mixture between white and red hairs, is lost in SHGC animals. In addition, SHGC animals present muscular hypoplasia, especially of the hind limbs, which prevents calves standing up within 2 or 3 days after birth and which is associated with unsteady stance and gait. However, affected animals have a normal vitality associated with a relatively higher resistance to intestinal infectious diseases compared to normal calves. Females can reproduce and initiate lactation but milk production is reduced because of the decreased physiological capacity (small size) of the animals. On the other hand, the remarkable udder morphology of SHGC females can be noticed.

Six SHGC animals, aged between 5 months and 4 years, were autopsied and evaluated for a wide range of biochemical and physiological parameters. Necropsic 

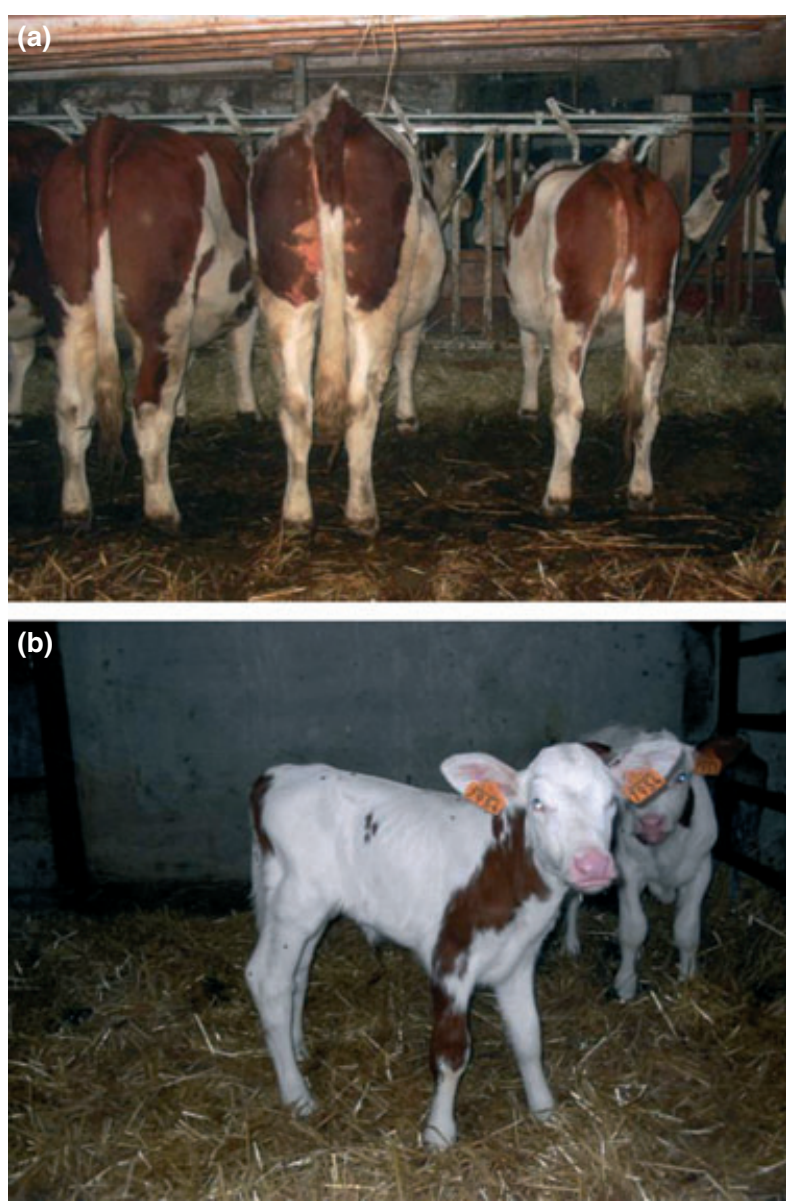

Figure 1 Presentation of the Generalized Caprine-like Hypoplasia Syndrome phenotype (SHGC). (a) Three heifers of the same age. The two on the left are normal while the one on the right is affected by SHGC. (b) A calf affected by SHGC. Note the typical white ears (normal animals have red ears).

evaluations and histological analyses revealed no lesion of diagnostic interest. All the other results were within the reference intervals, except for low GSH-Px activity of $79 \mathrm{U} / \mathrm{g}$ $\mathrm{Hb}$ (normal range 150-400 U/g Hb). To verify this selenium deficiency in SHGC animals, trace elements were measured in another laboratory on ten live SHGC calves, their ten dams and 20 other contemporary calves. On average, selenium deficiency was similar in the two groups of calves (GSH-Px concentrations of 221.8 and $213.3 \mathrm{U} / \mathrm{g}$ $\mathrm{Hb}$ respectively in SHGC and other contemporary calves). However, in the sample studied, the number of calves presenting a severe selenium deficiency was slightly higher in SHGC than in normal calves (30\% and 20\% respectively). The most severe selenium deficiency was observed in the dams. Thus, selenium deficiency seems to be a relatively general trend in the Montbéliarde population, which could originate from the quality of the fodder, at least in this case because all calves (normal and affected) were sampled from one specific geographical region (i.e. the East of France).
Analysis of the pedigree

We performed a pedigree analysis with PEDIG on 125 affected calves for which both paternal and maternal pedigree information was available. The 125 affected animals originated from 142 different parents, which can all be traced back to two sires, born in the 1950s. The two sires are six to 15 generations apart from the affected animals, and they are present several times in their pedigree, from two (once from the paternal way and once from the maternal way) to 22 times. We were not able to link together these two common ancestors because pedigree information in the previous generations is lacking.

All affected animals were born from phenotypically normal parents. Moreover, matings between affected females and normal sires always produced normal calves, suggesting that the mode of inheritance is not dominant. Therefore, the mode of inheritance seems likely to be autosomal recessive.

\section{Genome scan and fine mapping}

A genome scan was performed with a set of 140 publicly available microsatellite markers on 113 animals belonging to nine families. Non-parametric linkage (NPL) analysis was performed on each chromosome separately. The information content computed by GENEHUNTER was 0.49 on average and, except for BTA9 and BTA11, it was higher than 0.2 for most of the chromosomal segments (Fig. 2). Among the 140 markers, only two on BTA13, HUJ616 and ABS10, showed significant linkage with SHGC (NPL scores were 8.5 and 9.9 respectively; $P<10^{-3}$ ). The maximum NPL score was located near marker ABS1O (NPL score $=$ 10.3; $\left.P<10^{-3}\right)$. No significant linkage was detected on the other chromosomes (Fig. 2). This suggested that the locus causing SHGC is localized on BTA13 between HUJ616 and ABS10. These markers define an interval of approximately $35 \mathrm{cM}$.

To refine the localization of SHGC, 18 new markers were genotyped and the initial pedigree was extended with 148 other animals, forming a total of 261 animals belonging to 22 different families. The information content was higher than 0.69 for the whole region. Non-parametric linkage analysis confirmed the linkage between SHGC and this region of BTA13, with NPL scores higher than 6.44 for the whole interval. As shown in Fig. 3, maximum peak position was found between markers DIK2890 and DIK4350 (maximum NPL score $=24.07 ; P<10^{-13}$ ).

\section{Haplotyping and association tests}

Most likely haplotypes were computed with the MERLIN software for the 261 genotyped animals. For each family, the carrier haplotype was identified using the affected individuals. The study of recombinant animals contributed 


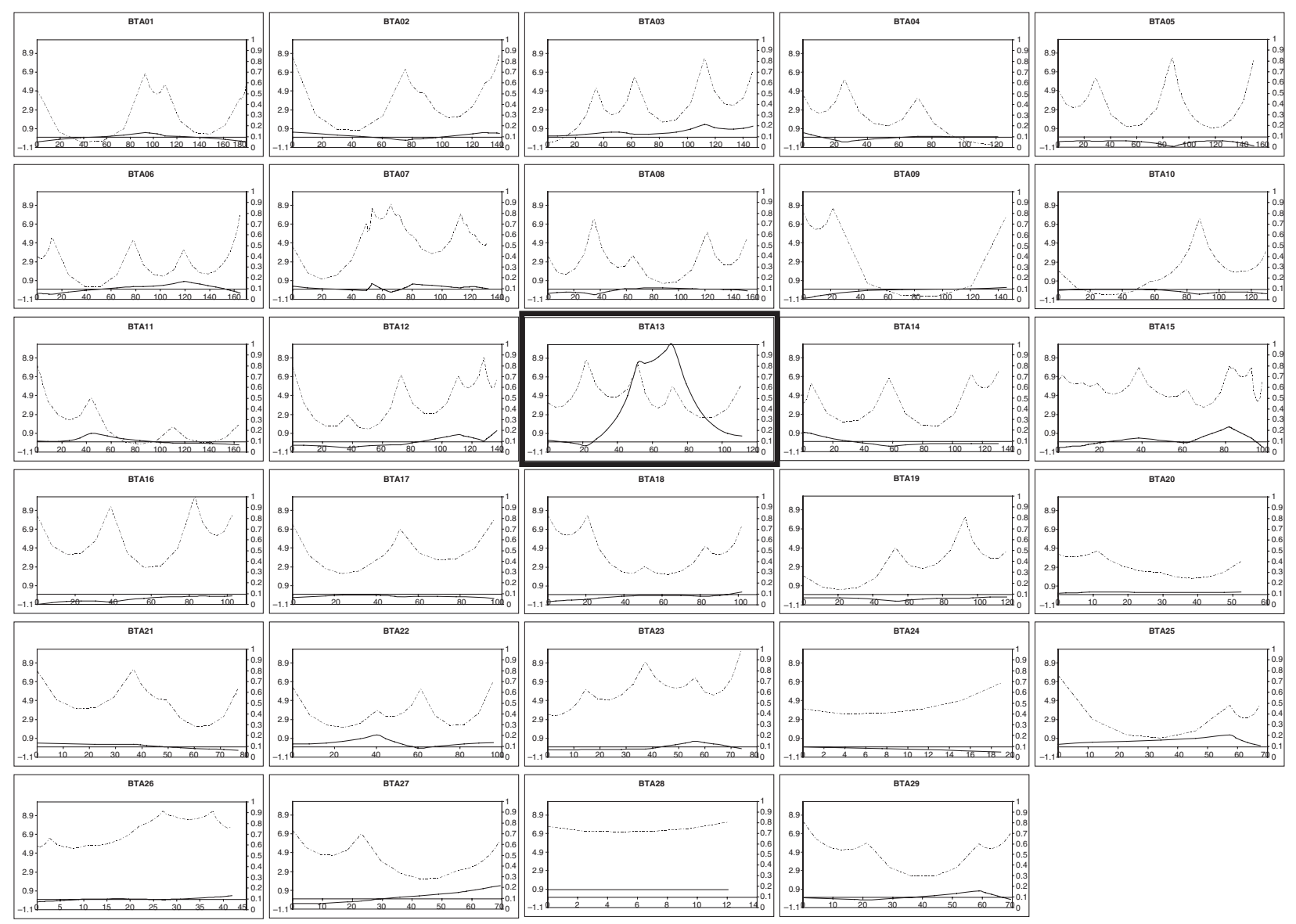

Figure 2 Non-parametric linkage analysis of the 29 bovine autosomes. The dotted curves represent the information content, with the scale on the right, and the full ones the non-parametric linkage score as calculated by GENEHUNTER, with the scale on the left. The $x$-axis represents the genetic distance on each chromosome. Linkage was found with BTA13.

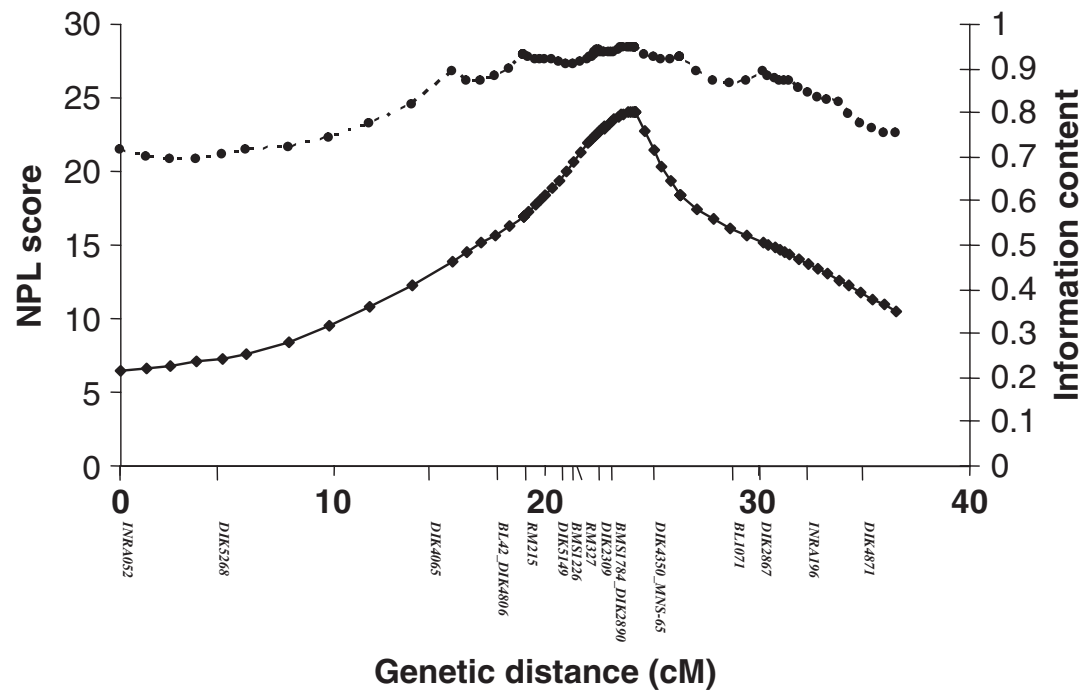

Figure 3 Non-parametric linkage analysis of the 35-cM interval of BTA13 isolated after the genome scan. The dotted curves represent the information content (with the scale on the right), and the full curves represent the non-parametric linkage score as calculated by GENEHUNTER (with the scale on the left). With the addition of new markers, linkage to BTA13 is confirmed, and the localization of Generalized Caprine-like Hypoplasia Syndrome is refined.

to identify a $\sim 6 \mathrm{cM}$ core IBD haplotype between markers DIK2890 and BL1071, shared by all the affected individuals on their paternal chromosome (Fig. 4). This result is in agreement with linkage analysis results.
We further performed family-based association tests using the FBAT software both under recessive and dominance models. The recessive model gave the best results, which confirms the hypothesis of a recessive mode of inheritance. 


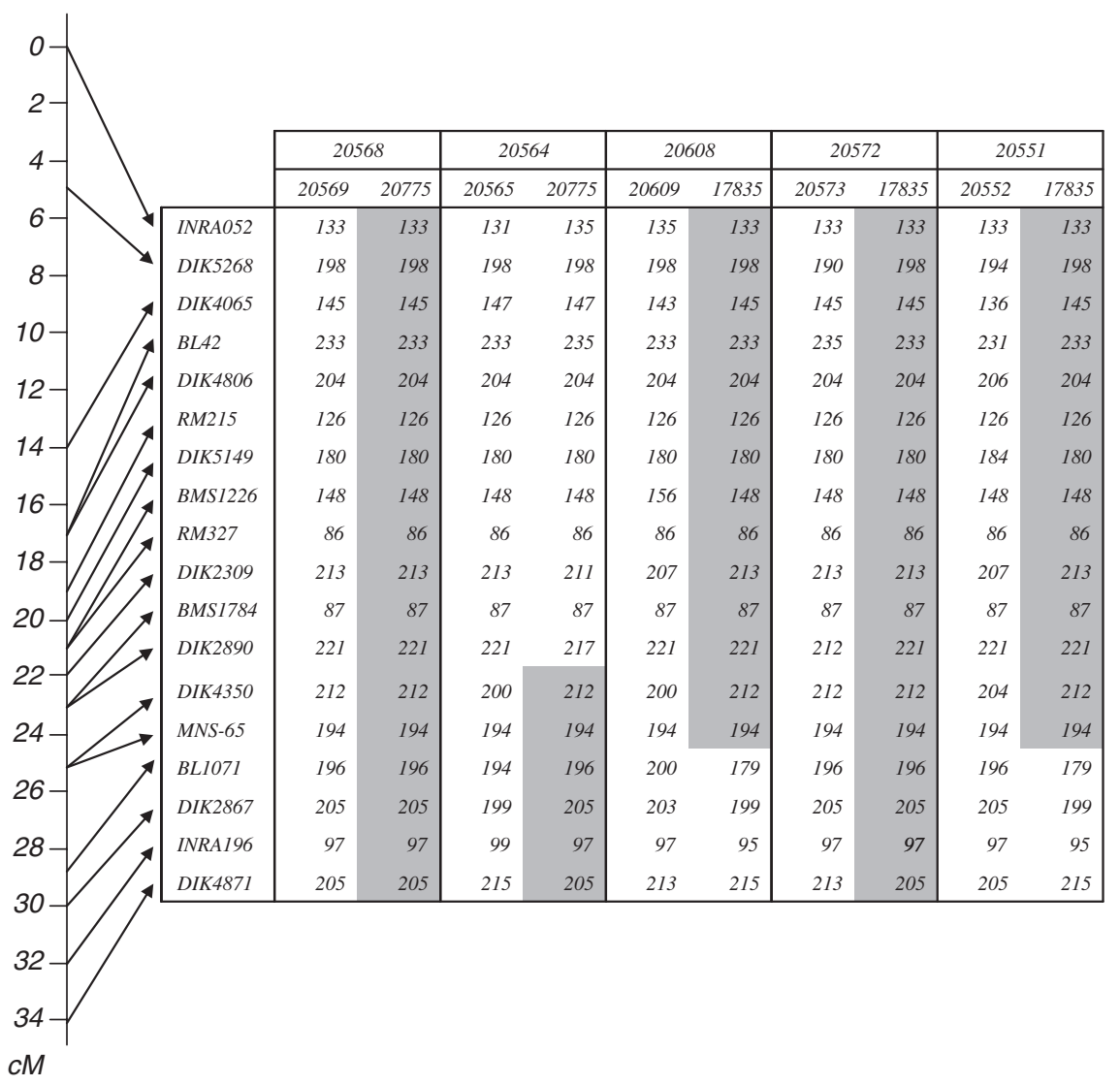

Figure 4 A sample of haplotypes of five Generalized Caprine-like Hypoplasia Syndrome (SHGC) animals (with maternal and paternal haplotypes for each animal) from two different sires: 20775 and 17835. Sire haplotypes are represented in grey. Some recombinants (animals 20608, 20551 and 20564) were useful to reduce the interval.

For ten of the 18 markers, a single allele associated with SHGC could be found $\left(P<10^{-6}\right)$. These alleles correspond to the alleles of the carrier haplotype found with the haplotype analysis described above.

\section{Construction of an integrated map of the region}

Seventeen microsatellites used in the analysis as well as 24 newly developed markers (genes identified by comparative mapping around and in the 6-cM interval containing SHGC) were mapped with the European RH panel (Williams et al. 2002). Additionally, we screened our bovine BAC library for eight microsatellites and for 14 from the 24 newly developed markers to anchor the region to our bovine physical map. The whole region was anchored to seven BAC contigs (Fig. 5). Using orthologous gene information, a comprehensive comparative map between BTA13, HSA20 and MMU2 was built (Fig. 5). The bovine gene order was found to be globally concordant among the three species for the region studied, with the exception of small inconsistencies remaining for three genes indicated by an arrow. These differences are due either to mapping errors or to the limited resolution of the radiation hybrid panel when marker density becomes too high. Nevertheless, because these genes were also mapped to the physical map, their inconsistent localizations were resolved precisely. For example, ASIP, which was mapped between PLUNC and E2F1 in the RH map, was located further in the physical map, between EI2FS2 and PROCR, in agreement with the order of HSA20 and MMU2.

The gene and marker order was also compared with the gene order of the bovine draft sequence (http://genome. ucsc.edu/). Many inconsistencies remain between the draft sequence and our integrated map, which are mainly due to the preliminary status of the current version of the bovine sequence assembly. The new assembly should provide important improvements and should resolve most inconsistencies with our map.

\section{Estimation of the frequency of SHGC in the Montbéliarde population}

To evaluate the frequency of SHGC in the Montbéliarde population, 463 sires representative of the whole Montbéliarde population were genotyped for the 18 additional markers. Haplotypes of these sires were computed using pedigree information, and their IBD probabilities with the core disease allele carrier IBD haplotype identified above 


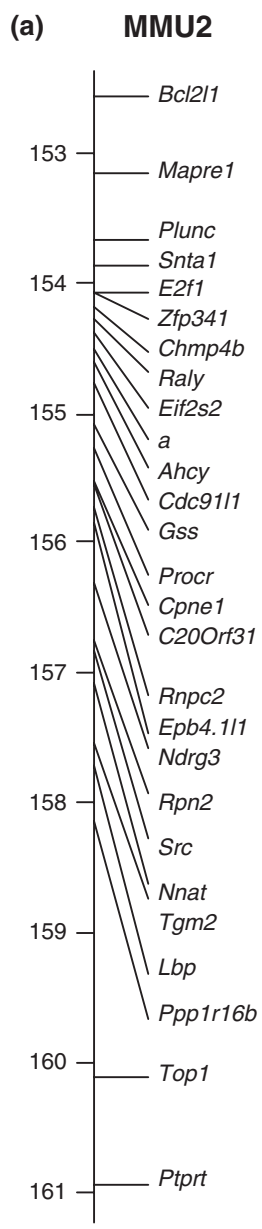

$\mathrm{Mb}$ (b) HSA20

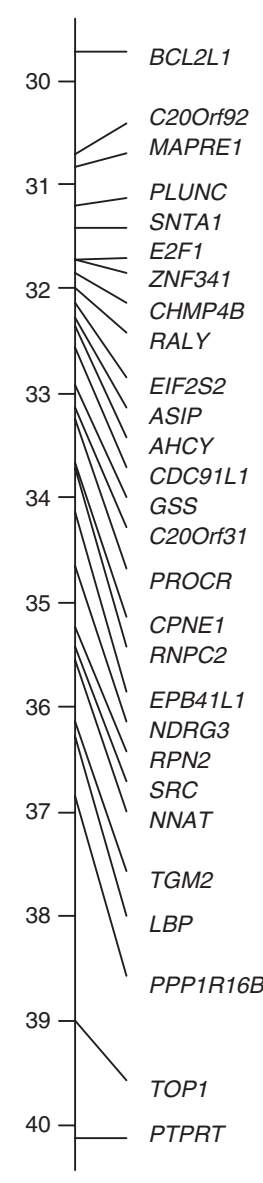

$\mathrm{Mb}$ (c) BTA13

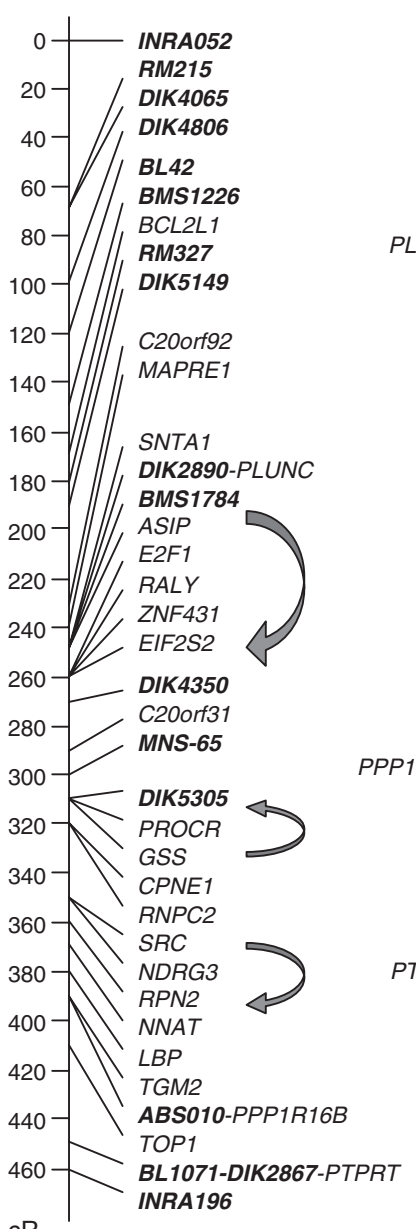

(d) BTA13

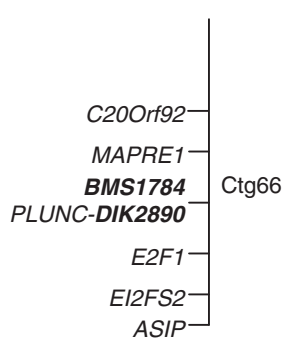

ASIP-
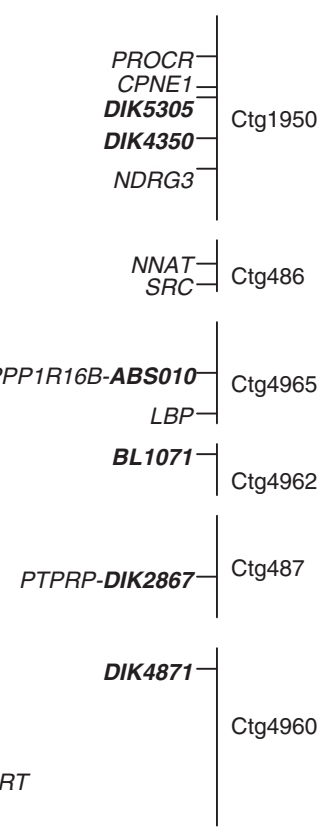

(e) BTA13

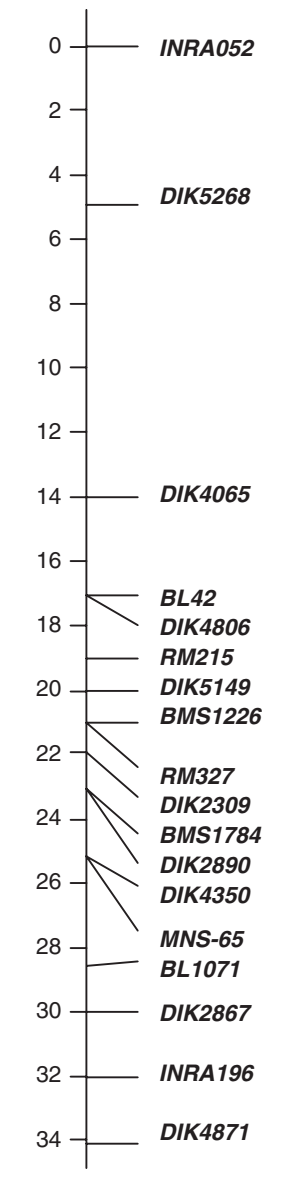

$\mathrm{CM}$

Figure 5 Comparative integrated map of the Generalized Caprine-like Hypoplasia Syndrome region in cattle and its conserved segments with mouse and man. (a) Map of mouse chromosome 2 (152 500 000-161 000000 bases). (b) Map of human chromosome 20 (30000 000-40 000 000 bases). (c) RH map produced with genes and markers of the SHGC region. Small inversions of the human and mouse order are indicated by an arrow. (d) Physical map of the region for the same loci. Loci are spread on seven contigs. (e) Genetic map of the 18 markers. Microsatellites are written in bold.

were estimated. These probabilities were higher than 0.9 and 0.75 respectively for 21 and 40 haplotypes (out of $463 \times 2=926$ analysed haplotypes). Thus, depending on the threshold considered, the carrier haplotype frequency ranges from 0.022 to 0.043 in the population (corresponding to $4.5-8.6 \%$ carrier sires among the 463 analysed).

\section{Discussion}

A new disease, SHGC, has recently emerged in the Montbéliarde breed population, the main symptoms being muscular hypoplasia, reduced body size and partial depigmentation. Several syndromes with these same symptoms have been described in human [Allan-HerndonDudley syndrome (Bialer et al. 1992)] and in mouse (mouse mutants dark, dds, myo5a and skc18), but none is totally similar to SHGC (i.e. none included all and exclusively the
SHGC symptoms). For this reason, a pure candidate gene approach strategy cannot be applied.

However, with the help of the BGDO, many affected calves together with their parents have been collected, which made it possible to initiate a regular genome scan and positional cloning strategy. Given that this disease was suspected to have an autosomal and recessive inheritance and that the parental phenotypes could not be always determined with certainty, non-parametric linkage analysis was the method of choice. This method was sufficiently robust to detect a significant linkage between SHGC and two markers of BTA13, separated by about $35 \mathrm{cM}$. No significant linkage with SHGC could be found with any other bovine chromosome, thus supporting the hypothesis of a monogenic disorder. Subsequent haplotype analysis and association test confirmed that the disease is autosomal recessive. Indeed, the addition of 18 new microsatellite 
markers allowed us to identify a core paternal carrier IBD haplotype spanning a $\sim 6 \mathrm{cM}$ region between markers DIK2890 and BL1071. Moreover, the frequency of SHGC in the Montbéliarde sire population was estimated and showed that $5-8 \%$ of the sires were SHGC carriers. This proportion is relatively significant, but is small enough to consider eradication of the disease in the breed: carrier sires can be excluded from the breeding program based on their genotypes for the critical interval containing the gene responsible for the disease.

This study demonstrates the essential role that the BGDO and the breeding organizations have had in the preliminary mapping of this disease. Once the samples were available in the laboratory, only 12 months were necessary to localize SHGC to an interval as narrow as $6 \mathrm{cM}$, to identify carrier haplotypes and to propose a strategy for the eradication of the disease. These positive results underline the relevance of the implementation of the BGDO and prove also that such an organization is highly valuable to tackle emergent abnormalities in cattle.

For the near future, several roads are open for further investigations on this new disease. First, it is necessary to continue the fine-mapping of the interval containing the SHGC locus, between microsatellite markers DIK2890 and BL1071. These markers were aligned to the bovine sequence by in silico $\mathrm{PCR}$, and respectively corresponded to the PLUNC and PTPRT genes. This $\sim 6 \mathrm{cM}$ interval on BTA13 is conserved with HSA20 (around 31280000 40150000 bases) and MMU2 (around 153590000 160980000 bases). This interval contains approximately 70 genes in human and mouse and, given the complexity of the disease phenotype, it is not possible to identify any obvious candidate gene. However, the presence of the agouti gene in the region conserved with the mouse genome and also mapped in the bovine interval should be noted. The agouti protein regulates pigmentation in the mouse hair follicle, but has also other pleiotropic effects (obesity, type 11 diabetes, increased somatic growth and tumorigenesis), which can be explained by the antagonism between other members of the melanocortin receptor family and the agouti protein (Voisey \& van Daal 2002). This gene is expressed in a wide range of tissues in cattle, suggesting that the bovine agouti gene could be involved in various physiological functions (Girardot et al. 2005). Nevertheless, besides its implication in hair pigmentation, it remains unclear how this gene could be responsible for the other symptoms like those observed in SHGC. Thus, positional cloning of SHGC should be pursued by reducing the critical interval. Once new polymorphic microsatellite markers are identified, the availability of several recombinant animals in the region of $6 \mathrm{cM}$ will help to refine this critical interval.

The second aspect, which needs to be examined more thoroughly, concerns the biochemical studies. These studies have revealed that SHGC animals, their mothers and other contemporary animals have a selenium deficiency. Sele- nium is an essential trace element, the deficiency of which causes muscle dysfunction or diseases, in cattle, sheep and human (Rederstorff et al. 2006). Selenium is incorporated in selenoproteins, which are involved in multiple metabolic pathways. Twenty-six different selenoproteins are currently described in higher eukaryotes, but none maps in the human or mouse region conserved with the bovine SHGC interval identified in our study. However, the possibility of non-described open reading frames in this region prevents us from excluding the presence of a new selenoprotein. Further bioinformatics studies based on the bovine draft sequence may provide supplementary information. Interestingly, it has also been shown that low dietary levels of selenium may cause changes in DNA methylation and induce tumorigenesis (Davis et al. 2000; Rodenhiser \& Mann 2006). Therefore, the study of DNA methylation patterns may represent a new line for the study of the gene responsible for SHGC.

\section{Acknowledgements}

The authors would like to thank LABOGENA (Yves Amigues \& Hélène Legros) for having generated the first (15 820) genotypes used for the genome scan; Michel Tissier (Umotest) for providing semen samples of Montbéliarde sires and for his involvement in the project which permitted us to collect a large number of affected SHGC calves; and MarieAnge Duyck (INRA-LGbC) for her help with the DNA extractions. Hélène Hayes (INRA-LGbC) is especially acknowledged for the English revision of the manuscript. A. Duchesne is a PhD student supported by LABOGENA and by the INRA Department of Animal Genetics.

\section{References}

Abecasis G.R., Cherny S.S., Cookson W.O. \& Cardon L.R. (2002) MERLIN-rapid analysis of dense genetic maps using sparse gene flow trees. Nature Genetics 30, 97-101.

Bialer M.G., Lawrence L., Stevenson R.E., Silverberg G., Williams M.K., Arena J.F., Lubs H.A. \& Schwartz C.E. (1992) AllanHerndon-Dudley syndrome: clinical and linkage studies on a second family. American Journal of Medical Genetics 43, 491-7.

Boichard D. (2002) PEDIG: a FORTRAN package for pedigree analysis suited for large populations. In: 7th World Congress on Genetics Applied to Livestock Production, Communication No. 28-13 (CD-ROM).

Bolard M. \& Boichard D. (2002) Use of maternal information for QTL detection in a (grand)daughter design. Genetics Selection Evolution 34, 335-52.

Davis C.D., Uthus E.O. \& Finley J.W. (2000) Dietary selenium and arsenic affect DNA methylation in vitro in Caco-2 cells and in vivo in rat liver and colon. Journal of Nutrition 130, 2903-9.

Ducos A., Eggen A. \& Boichard D. (2004) Implementation of the French Bovine Genetic Disease Programme. In: European Association for Animal Production - 55th Annual Meeting, p. 82. Wageningen Academic Publishers, Wageningen. 
Eggen A., Gautier M., Billaut A., Petit E., Hayes H., Laurent P., Urban C., Pfister-Genskow M., Eilertsen K. \& Bishop M.D. (2001) Construction and characterization of a bovine BAC library with four genome-equivalent coverage. Genetics Selection Evolution 33, 543-8.

Gautier M., Hayes H. \& Eggen A. (2002) An extensive and comprehensive radiation hybrid map of bovine chromosome 15: comparison with human chromosome 11. Mammalian Genome 13, 316-9.

Gautier M., Barcelona R.R., Fritz S., Grohs C., Druet T., Boichard D., Eggen A. \& Meuwissen T.H. (2006) Fine mapping and physical characterization of two linked quantitative trait loci affecting milk fat yield in dairy cattle on BTA26. Genetics 172, 425-36.

Girardot M., Martin J., Guibert S., Leveziel H., Julien R. \& Oulmouden A. (2005) Widespread expression of the bovine agouti gene results from at least three alternative promoters. Pigment Cell Research 18, 34-41.

de Givry S., Bouchez M., Chabrier P., Milan D. \& Schiex T. (2005) CARTHAGENE: multipopulation integrated genetic and radiation hybrid mapping. Bioinformatics 21, 1703-4.

Hartl D.L. (1994) Génétique des populations. Flammarion Médecine Sciences.

Huston K. (1993) Heritability and diagnosis of congenital abnormalities in food animals. Veterinary Clinics of North America: Food Animal Practice 9, 1-9.

Ihara N., Takasuga A., Mizoshita K. et al. (2004) A comprehensive genetic map of the cattle genome based on 3802 microsatellites. Genome Research 14, 1987-98.

Kruglyak L., Daly M.J., Reeve-Daly M.P. \& Lander E.S. (1996) Parametric and nonparametric linkage analysis: a unified multipoint approach. American Journal of Human Genetics 58, 1347-63.

Lake S.L., Blacker D. \& Laird N.M. (2000) Family-based tests of association in the presence of linkage. American Journal of Human Genetics 67, 1515-25.

Meuwissen T.H. \& Goddard M.E. (2001) Prediction of identity by descent probabilities from marker-haplotypes. Genetics Selection Evolution 33, 605-34.

Millar P., Lauvergne J.J. \& Dolling C. (2000) Mendelian Inheritance in Cattle 2000, EAAP Publication No. 101. Wageningen Academic Publishers, Wageningen.

Moureaux S., Boichard D. \& Verrier E. (2000) Utilisation de l'information génétique pour l'estimation de la variabilité génétique de huit races bovines laitières françaises d'extension nationale ou régionale (Use of pedigree information to estimate genetic variability of eight national or regional French dairy cattle breeds). In: 7èmes Rencontres Recherches Ruminants, pp. 147-52. Institut de l'Elevage - INRA.

Nagahata H. (2004) Bovine leukocyte adhesion deficiency (BLAD): a review. Journal of Veterinary Medical Science 66, 1475-82.

Rederstorff M., Krol A. \& Lescure A. (2006) Understanding the importance of selenium and selenoproteins in muscle function. Cellular and Molecular Life Sciences 63, 52-9.

Rodenhiser D. \& Mann M. (2006) Epigenetics and human disease: translating basic biology into clinical applications. Canadian Medical Association Journal 174, 341-8.

Schibler L., Roig A., Mahe M.F., Save J.C., Gautier M., Taourit S., Boichard D., Eggen A. \& Cribiu E.P. (2004) A first generation bovine BAC-based physical map. Genetics Selection Evolution 36, 105-22.

Thompson J.R., Everett R.W. \& Hammerschmidt N.L. (2000) Effects of inbreeding on production and survival in Holsteins. Journal of Dairy Science 83, 1856-64.

Thomsen B., Horn P., Panitz F., Bendixen E., Petersen A.H., Holm L.E., Nielsen V.H., Agerholm J.S., Arnbjerg J. \& Bendixen C. (2006) A missense mutation in the bovine SLC35A3 gene, encoding a UDP-N-acetylglucosamine transporter, causes complex vertebral malformation. Genome Research 16, 97-105.

Voisey J. \& van Daal A. (2002) Agouti: from mouse to man, from skin to fat. Pigment Cell Research 15, 10-8.

Williams J.L., Eggen A., Ferretti L. et al. (2002) A bovine wholegenome radiation hybrid panel and outline map. Mammalian Genome 13, 469-74.

\section{Supplementary material}

The following supplementary material is available for this article online from http://www.blackwell-synergy.com/doi/ full/10.1111/j.1365-2052.2007.01688.x

Table S1 Characteristics of the 140 microsatellite markers used in the genome scan. Primer pair sequences are publicly available.

Table S2 Characteristics of 18 new microsatellite markers used in the further localization of SHGC.

Please note: Blackwell Publishing is not responsible for the content or functionality of any supplementary materials supplied by the authors. 